\title{
Impact of Rational Logging on the Regeneration of Plant Species in the South-West of the Central African Republic
}

\author{
Innocent Kossa Koyakodo ${ }^{1, ~ *, ~ F i d e ̀ l e ~ M i a l o u n d a m a ~}{ }^{2}$, Guy Gildas Sosthène Zima ${ }^{3}$ \\ ${ }^{1}$ Higher Institute of Rural Development (ISDR), University of Bangui, Mbaïki, Central African Republic \\ ${ }^{2}$ Doctoral Training in Natural Sciences Agronomy, Faculty of Sciences, Marien Ngouabi University, Brazzaville, Congo \\ ${ }^{3}$ Department of Plant Biodiversity, Faculty of Science, University of Bangui, Central African Republic
}

Email address:

innocentkossa@yahoo.fr (I. K. Koyakodo)

${ }^{*}$ Corresponding author

\section{To cite this article:}

Innocent Kossa Koyakodo, Fidèle Mialoundama, Guy Gildas Sosthène Zima. Impact of Rational Logging on the Regeneration of Plant Species in the South-West of the Central African Republic. International Journal of Biomedical Materials Research. Vol. 8, No. 1, 2020, pp. 1-7. doi: 10.11648/j.jibmr.20200801.11

Received: March 18, 2019; Accepted: June 23, 2019; Published: May 18, 2020

\begin{abstract}
Nowadays, logging must be practiced in a rational manner in order to reduce the negative impacts on the environment and thus leading to the perpetuation of natural resources. This study was carried out in one of the concessions of logging companyVicwood Centrafrique "VICA»" in the South-West of the Central African Republic. The objective was to evaluate the effects of rational logging on the regeneration of plant species. From the different methodologies (bibliographic review, semi-structured interview, technical evaluation), data were collected, processed and analysed. Results obtained showed that the proportion of deforested area in an annual cutting base within the framework of a sustainable exploitation is $0.27 \%$ for an area of 100ha. Strict compliance with the upstream planning based on a good exploitation inventory made it possible to define the characteristics of the roads to be built which will have a low impact on the regeneration of the plant resources. The beneficial role of the management team to support the units on the field according to the management rules focused on (i) social aspects, (ii) mapping Geographical Information System and (iii) the traceability system for monitoring of the log from the prospecting period to when evacuation takes place. This has effectively contributed to the sustainable management of these ecosystems for the benefit of the future generation.
\end{abstract}

Keywords: Rational Logging, Regeneration, Plant Species, Central African Republic

\section{Introduction}

Forests in Central Africa cover an area of about 241 million hectares, more than half of which is the Congo Basin forest [1]. This is the second largest wet forest in the world after the Amazon, covering about $12 \%$ of tropical forest [2]. The Central African Republic (CAR) is part of the Congo Basin countries and covers an area of approximately 623,000 $\mathrm{km}^{2}$. It has a relatively small forest area of about 5 million hectares, which represents $8 \%$ of the national territory. In terms of commercially valuable species such as Sapelli, Ayous and Sipo, its forests are among the richest in Central Africa and from an ecological point of view, it represents the crossroads where the bio-geographical regions from Central Africa come together [3]. The forest of the South West of
Central African Republic occupies an area of 3.8 ha and currently represents the only forest area open to industrial exploitation. The sustainable management of this forest ecosystem is governed by a forest code drawn up in 2008 [4] with an exclusive focus on the allocation of Exploitation and Development Permits (AEPs) to forest companies whose development is part of integrated forest management strategies, sustaining biodiversity and protecting the ecosystems while combining exploitation and rational management of the forest. To date, there are fourteen (14) Exploitation and Development Permits granted to loggers of which thirteen (13) are operational [5] and [6].

Rational logging is based on minimizing the negative economic, ecological and social impacts of industrial logging through the implementation of the low impact logging (EFI) method. The scientific information obtained by some PEAs 
from the implementation of this method is not yet valued at the national and regional levels. There is an urgent need to conduct participatory research to fill these gaps because in our knowledge the plant species of the Southwest forest plays a key role in the hydrological cycle, sequestration of carbon, the protection of cultural diversity and the contribution of various products. The problem statement of our study is based on one point: What is the real impact of rational exploitation on the reconstruction and regeneration of plant species in the South West of the Central African Republic? The results of this work will allow us to answer this main question.

The objective of the study is to evaluate the effects of rational logging on the reconstruction and regeneration of plant species in the south-west of the Central African Republic. The hypothesis of this study: "Rational logging does not contribute to the reconstruction and regeneration of plant species in south western CAR".

\section{Methodology}

\subsection{Study Zone}

This study was carried out in the concession of the Vicwood Forest Company (VICA) located in the South West of the Central African Republic, more specifically on the Exploitation and Development Permit (PEA 184). PEA 184 lies between latitude $4^{\circ} 00$ 'and $4^{\circ} 40^{\prime}$ north and between longitude $15^{\circ} 35$ 'and $16^{\circ} 15^{\prime}$ East in Mambéré-Kadéi prefecture. This license was granted to VICA by attribution decree $\mathrm{N}^{\circ} 04.046$ of February 12th, 2004 and extended by the mail No 062 / MEFCPE / DIRCAB / DGEFCP.

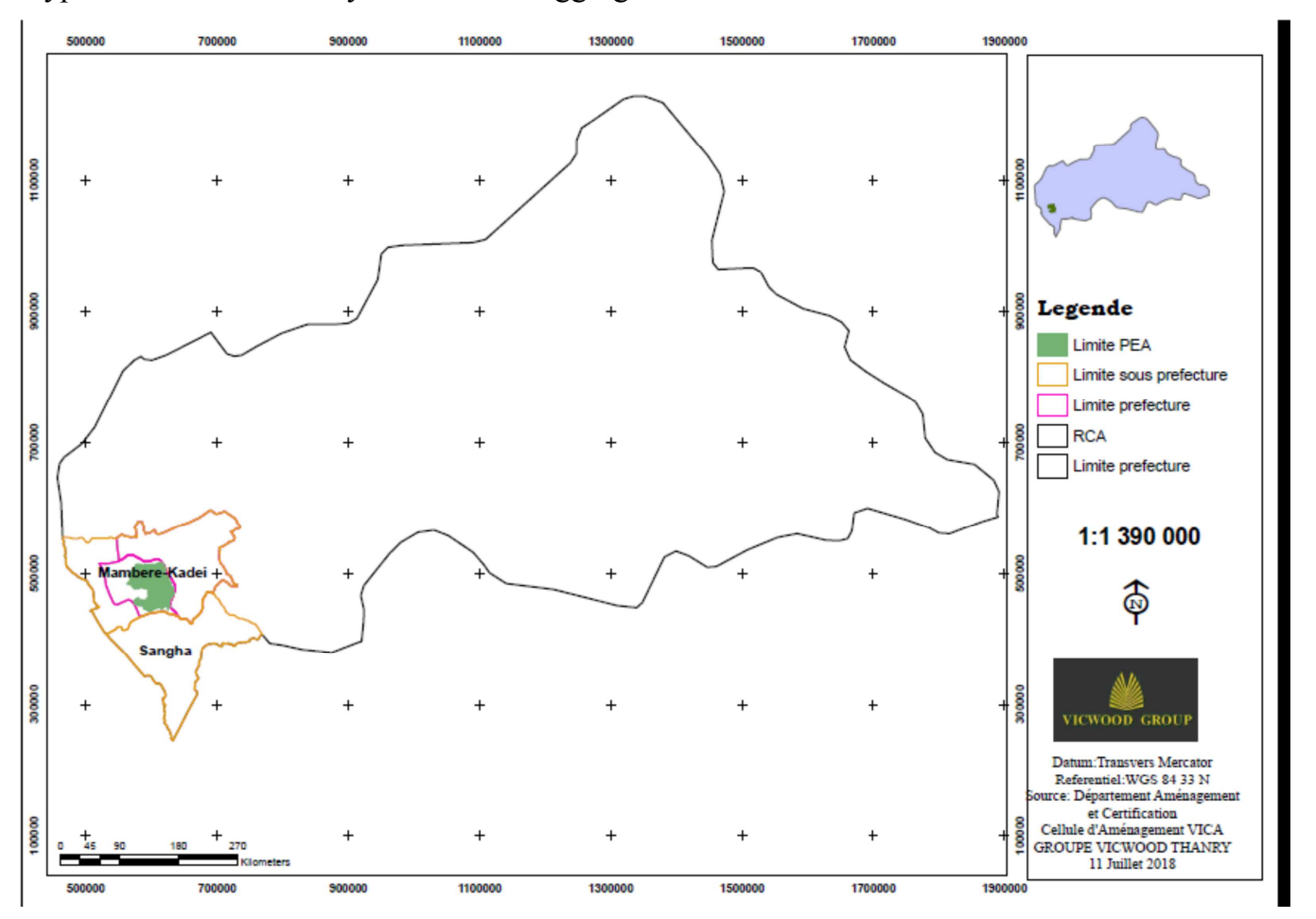

Figure 1. Location of the study area.

\subsection{Data Collection}

It is based on two major components. The first concerns the literature review. In addition to identifying how previous work was addressed, it also addresses the deficiencies of sustainable logging and regeneration of plant species in the South West of the Central African Republic as well as elsewhere. The second component consisted of collecting field data that took place from November 2018 to February 2019 and their processing. A questionnaire (semi-directive interview) based on the objectives of the study was designed then administered to collect data on environmental effects. The Microsoft Excel software was used to tally the questionnaire and analyse the results. This step made it possible to measure the level of exploitation impact on the regeneration of biological resources.

\subsection{Evaluation Technique}

To evaluate this exploitation with all its impact, a sampling whose size is the annual cutting base 12 of the $3^{\text {rd }}$ Forest Management Unit belonging to the UFG of the PEA 184 was chosen. This base was open for exploitation in June 2018 and still remains open until February 2019. On this base, it was first of all important to see the upstream exploitation inventories which constitute the base of a farm, if well done will give the result of the density of existing resources on the annual cutting basis. The planning that follows the inventories is also an important axis in forecasting different operations. Planning in the exploitation project is then look into.

A post-exploitation follow-up aims to appreciate the felling technique, the criteria with their different stages. The 
control of stumps to assess traceability is also an evaluation tool. For this purpose a map to monitor the operations is required to assess the site.

\section{Results}

\subsection{Inventory of Species to Exploit}

Species exploitation inventories are made according to the standards from the document designed by the Ministry of Waters, Forests, Hunting and Fishing. A resource map was established for this purpose indicating the density and their distribution (Figure 2). The company that has to operate on this base, presented beforehand a management document presenting a calendar of activities called Annual Operating Plan. The document is examined by a validation commission set up by the Ministry of Water, Forestry, Hunting and Fishing.

To succeed in this work, planning was put in place. In this planning there is the road network follows by a felling projection and skid track.

\subsection{Operational Planning}

It consisted of tracing roads or building new roads. Three (3) kinds of forest tracks will be opened for the exploitation of the $\mathrm{AAC}_{-} 12$ : the main tracks, the secondary tracks and the tertiary tracks (braces).

\subsubsection{The Main or Permanent Slopes}

They are roads (or the public road network) that provide the link between the factory and the operating AAC. They are used for several years to allow access to different felling sites. The total length of the main tracks in the AAC_12 is estimated at 5,250 Km.

\subsubsection{Secondary Tracks}

They are roads specific to a felling site. They are used during the operating life of the AAC. The planned length for this category of roads in the AAC 12 is $33.5 \mathrm{Km}$

\subsubsection{Tertiary Tracks or Operating Braces}

They link a main or secondary track to one or more wood parks. Generally, they are only used for a few weeks. The length of the tertiary tracks in the site $\mathrm{N}^{\circ} 12$ is estimated at 8 $\mathrm{km}$.

The widths planned for the different types of tracks are as follows:

1. Main track: $20 \mathrm{~m}$

2. Secondary tracks: $15 \mathrm{~m}$

3. Tertiary: $10 \mathrm{~m}$

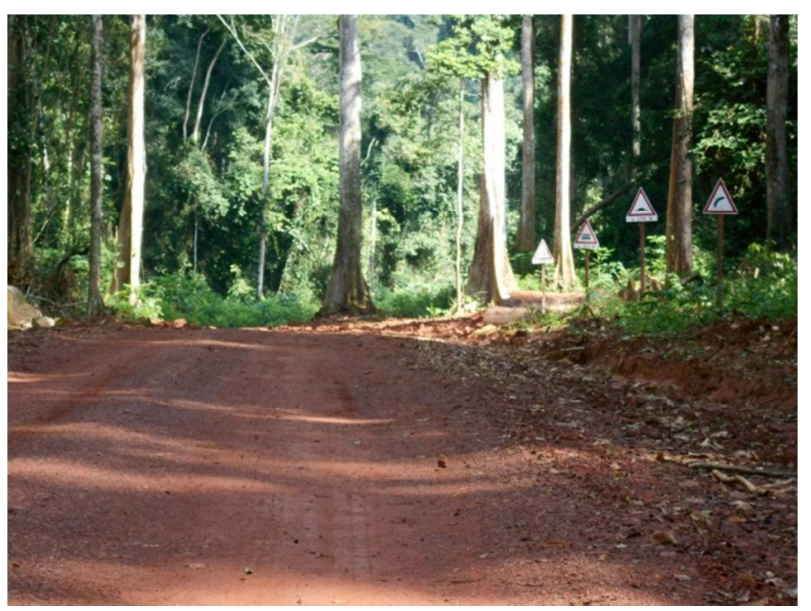

Figure 2. Operation Road on the Annual felling site 1. Source: Innocent Kossa, 2019.

\subsection{Characteristic of Roads and Opening Impacts}

Rational logging has a low impact on the degradation of plant species. In the case of the annual cutting base, the proportion of deforested area is $0.27 \%$, which is too low, reflecting a low- exploitation impact of biological resources. It allows plant species to re-establish and regenerate quickly.

Table 1. Characteristics of roads and opening impact.

\begin{tabular}{lllll}
\hline Road types & Length $(\mathbf{m})$ & Proportion \% & Deforested area (ha) & Proportions\% relative to area of AAC \\
\hline Main Road & 5250 & 11 & 10,5 & 0,04 \\
Secondary Road & 33500 & 72 & 50,25 & 0,20 \\
Braces & 8000 & 17 & 8 & 0,03 \\
Total & 46750 & 100,00 & 68,75 & 0,27 \\
\hline
\end{tabular}

\subsection{Impact of Felling on Plant Species}

In order to minimize the effects of felling on plant species, it came out that this is done by skilled workers. The felling techniques were applied leading to a directional felling respecting the felling criteria listed in the "regional low impact logging code". Each operator in charge of felling is evaluated monthly according to these quality criteria, also incentives are fixed taking into account the quality and then the yield.

Table 2. Evaluation Results in June 2018 for operator in charge of felling.

\begin{tabular}{llllll}
\hline & DEMOU & DIBO & MOKILI & NGATI \\
\hline Month & June & June & June & June & 1.8 \\
Direction of fall & 1 & 2 & 2 & 2 & 2 \\
Height of stump & 2 & 2 & 2 & 2 & 2 \\
Egobelage & 1 & 2 & 3.7 & 3.9 & 2 \\
Notch chamfer & 3.8 & 3.8 & 3.7 & 2 \\
\hline
\end{tabular}




\begin{tabular}{llllll}
\hline & DEMOU & DIBO & MOKILI & NGATI & ONEKEZOUA \\
\hline Hinge & 3 & 3 & 2.8 & 2.7 & 2.8 \\
Shoulder + sapwood cut & 2 & 2 & 2 & 2 & 1 \\
Hinge separation & 1 & 1 & 1 & 1 & 1 \\
Felling cut & 1 & 1 & 1 & 3 & 2.5 \\
Moy/20 & 2.8 & 2.8 & 19 & 19.4 & 19 \\
\hline
\end{tabular}
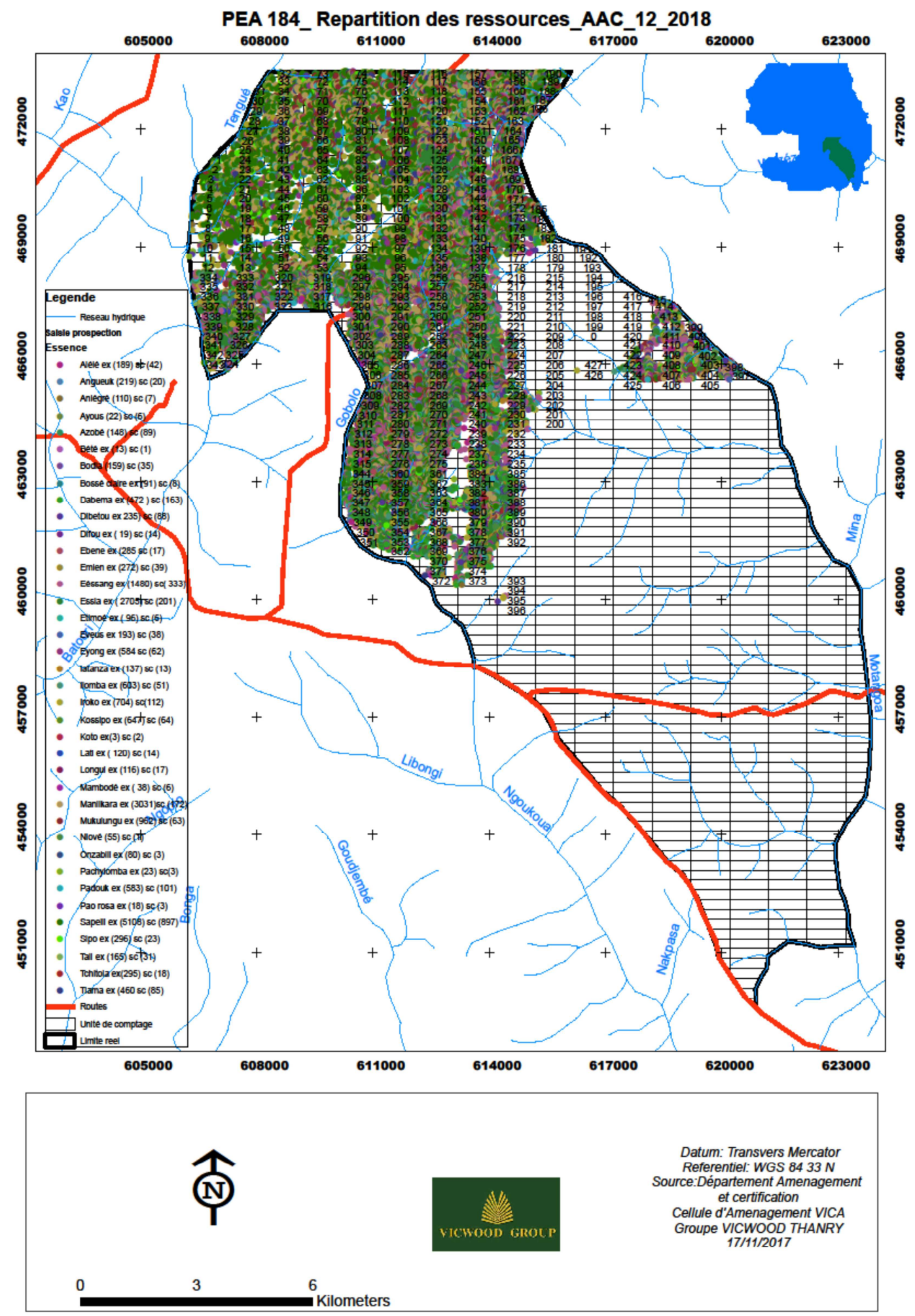

Figure 3. Distribution of species on the annual cutting. 


\subsection{Operation Monitoring}

In order to follow up an exploitation, a map is published every week. Figure 3 shows the monitoring operations that took place on February 23, 2019. It is updated weekly. The table at the bottom of the map explains the different colours of the follow-up map.

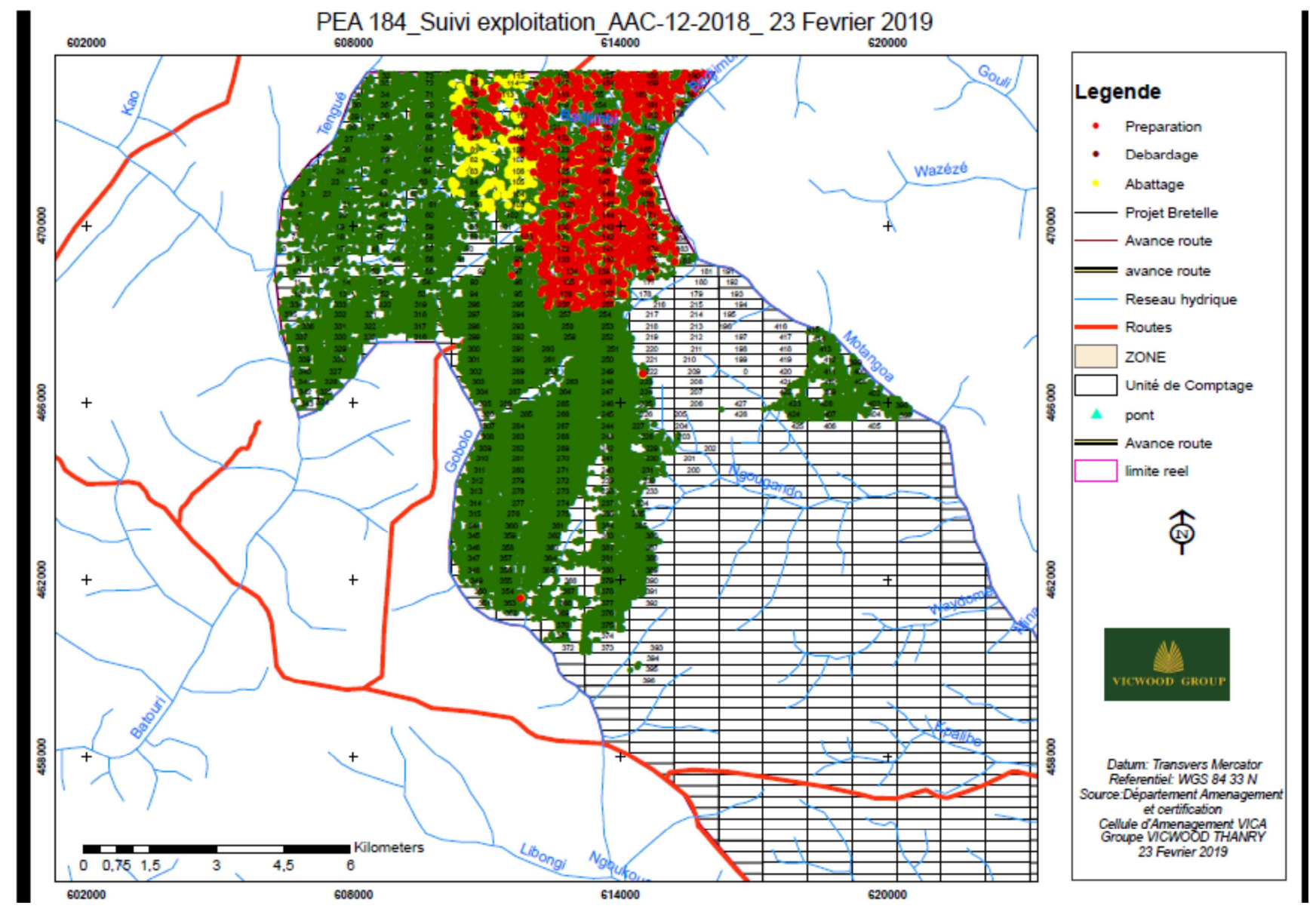

Figure 4. Monitoring and exploitation map as of February 23, 2019.

Table 3. Legend of the farm monitoring map.

\begin{tabular}{|c|c|}
\hline legends & comments \\
\hline Green Point & Tree identified during the exploitation inventory and trees retained with a diameter $>$ to the MED (Minimum Exploitability Diameter) \\
\hline Yellow point & on the felling area waiting to be cleared by heavy engines on Forest Park \\
\hline Orange point & Means that the log from the felled tree has been cut in the forest, cubed and skidded on the forest park by engines \\
\hline Red Point & $\begin{array}{l}\text { Means that the log fell in the wood park has been prepared (export or sawmill), cubed and is ready to be loaded onto a logging truck to } \\
\text { be evacuated }\end{array}$ \\
\hline
\end{tabular}

\subsection{Stem Control}

It allows traceability of exploited timber. On the site there is a traceability system that has been set up to monitor the operation. This monitoring is based on the internal Trace software. Trace is a software allowing the monitoring and the traceability of the woods from the exploitation in the forest until the boarding in the port of Douala, while passing by the transformation. This internal software was developed from Access in 2003, it is fed from daily data records produced by the various production teams. All the data is sent daily to the IT department of the Directorate General and compiled on a server that summarizes the data of the site. This system has been validated by several verification bodies (SGS, Bureau Veritas and Rainforest Alliance) on other sites of the group and meets the requirements of the TLTV, OLB and VLC standards.

\subsection{Skidder Track and Wood Park}

In order to reduce the impact of exploitation on the reconstruction and regeneration of plant species, logging tracks are planned. The felled woods are not skidded anyhow. In a given pocket, several skidders use the same passage. This practice minimizes or reduces negative impacts and promotes the development of plant species. It was noted during this study that no skidding passes through the stream or streams. 


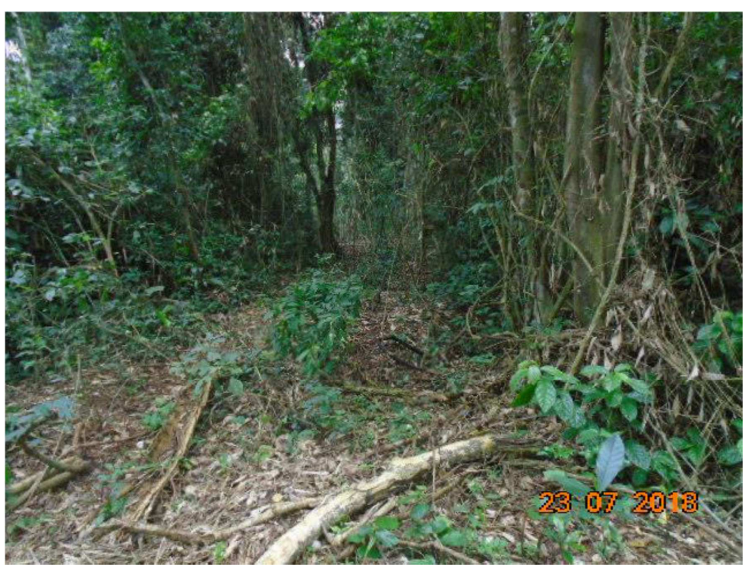

Figure 5. Skidding trail from planning Source: Innocent Kossa.

Timber yards are open for log preparation and storage prior to loading onto trucks. The parks are distributed fairly evenly, their number depending on the density of the resource and the topography of the land in order to limit the length of skid trails that must not exceed $500 \mathrm{~m}$. They are open on flat land and placed away from streams and springs at a minimum distance of $30 \mathrm{~m}$ from streams.

A total of thirty (39) wood parks are planned and open for AAC_12.

\section{Table 4. Impact of Park Opening.}

\begin{tabular}{ll}
\hline Number of parks planned & 39 \\
Average deforested area per park & 0,75 ha \\
Total area deforested by all the parks & 29,25 ha \\
Proportion to AAC area & $0,11 \%$ \\
\hline
\end{tabular}

\section{Discussion}

The central region is characterized by limited deforestation rates, resulting from localized logging associated with shifting agricultural activities [7] and [8]. Rational logging plays a very important role in the regeneration process of plant species [9]; [10] and [11]. This study shows that inventories provide a strategic basis for sustainable exploitation. They not only allow to materialize the limits of the Annual cut site; but also to carry out forest stratification, determine the topography, the orientation of the main rivers and the distribution of resources on the said base.

The data obtained from the deforested area $(0.27 \%)$ corroborate the data of several forest companies certified using FSC, FLEGT standards and those provided for by the regional code of low impact exploitation in West and Central Africa. in the order of 0.25 to $0.30 \%$ [12]. The hinge of all these works is a dynamic development area. Within this area, the tasks must be distributed as defined in the Management Plan [13]. The planner takes care of inventory and planning work to achieve the expected results. The social mediator for the monitoring of the social component by also involving the surrounding populations to accept the limits of the series of production [14]. The cartographer does his best so that the teams at each level have maps according to their objectives (inventory map, planning map, road network map, map allowing the felling, map allowing the skidding and even a tracking map). This arrangement was observed within the Congolese Industrial Wood in Congo and in many companies selling their timber in Europe (Rougier, Thanry, etc.). According to a study [15] and [16], adherence to these fundamental principles of management contributes to sustainable management of the forest ecosystem.

It was found that a road well done following the required standards led to less negative impacts. The roads are oriented from West to East with lighting accompanied by drains and evacuation channels. When felling trees, good work techniques are implemented not only to create a safe work environment, but also to be more effective in ensuring the safety of everybody. Periodic evaluation of the operators in charge of felling trees allows continuous monitoring. All these provisions are similar in all companies concerned using an environmentally friendly exploitation. From all these data, the assumption of this stipulation that: "The rational logging does not contribute to the reconstruction and regeneration of plant species in south western CAR" is rejected. On the contrary, rational logging contributes to regeneration of plant species.

\section{Conclusion}

In this study, logging alone is not a cause of forest degradation. The results obtained from the adopted methodologies show that the area deforested at an annual base of 100 ha is $0.27 \%$, thanks to the application of low impact logging techniques. The company has competent departments with a competent staff and adequate materials. These skills are largely based on building the internal and external capacity of its staff and strict compliance with established management documents. Regular monitoring by a post-production team will appreciate the work done upstream in order to maintain the course for sustainable resources leading to sustainable management. The implementation of the FLEGT process (meaning...) as well as the steps of certification, constitute the channels for a responsible exploitation. This responsible management will lead to the maintenance of the functions of the forest which are only economic, ecological and social.

\section{References}

[1] FAO, 2003. Regional Low-Impact Code in West and Central Africa, 14 pp.

[2] Mayaux P., Achard F. and Malingreau J. P., 1998. Global tropical forest area measurements derived from coarse resolution satellite imagery: a comparison with other approaches. Environmental Conservation, 25, 37-52.

[3] Mayaux P., Bartholomew E., Massart M., Vancutsem C., Cabral A., Nonguierma A., Diallo O., Pretorius C., Thompson M., Cherlet M., Pekel JF, Defourny P., Vasconcelos M., DiGregorio A., Fritz S., De Grandi G., Elvidge C., Vogt P. and Belward A., 2003. A Land Cover Map of Africa - Map of the Land Cover of Africa, EUR 20665, EN (European Commission, Luxembourg), 20 pp. 
[4] Ministry of Water and Forests, 2008. Forest Code of the Central African Republic, 14 pp.

[5] Ingram V., and Bongers G., 2009. Valuation of Non-Timber Forest Product Chains in Congo Basin: A methodology for valuation. Yaoundé, Cameroon: FAO-CIFOR-SNV-World Agroforestry Center-COMIFAC.

[6] Hansen M. C., Roy D. P., Lindquist E., Adusei B., Justice C. O., Altstatt A., 2008. A method for integrating MODIS and Landsat data for systematic monitoring of forest cover and change in Congo Basin. Remote Sensing of Environment, 112 (5), 2495-2513.

[7] ITTO, 2003. OAB-ITTO Principles, Criteria and Indicators of Sustainable Management of Tropical Forests in Africa. Series, ITTO Policy Development N ${ }^{\circ} 14$.

[8] Andersen, P., and S. Shimorawa. 2007. "Rural Infrastructure and Agricultural Development." In Rethinking Infrastructure for Development. Annual World Bank Conference on Development Economics.

[9] Angelsen, A., M. Brockhaus, M. Kanninen, E. Sills, W. D. Sunderlin, and S. Wertz-Kanounnikoff, eds. 2009. Realizing REDD +, National Strategy and Policy Options.

[10] Bogor, Indonesia: CIFOR. Atyi, R. E., D. Devers, C. de Wasseige, and F. Maisels. 2009. "Chapter 1: State of Central African Forests: Subregional Synthesis." In State of Forests 2008, OFAC-COMIFAC.

[11] Havlík, P., AU Schneider, E. Schmid, H. Boettcher, S. Fritz, R. Skalský, K. Aoki, S. de Cara, G. Kindermann, F. Kraxner, S.
Leduc, I. McCallum, A. Mosnier, T. Sauer, and M. Obersteiner 2011. "Global Land-Use Implications of First and Second Generation Biofuels Targets." Energy Policy 39 (10): 5690702 .

[12] Beck J. P., 2010. Land-use planning at the landscape scale: Central African Regional Program for the Environment (CARPE). In: Yanggen D., Angu K. and Tchamou N. (Eds), 2010. Landscape-Scale Conservation in the Congo Basin. Lessons Learned from the Central African Regional Program for the Environment (CARPE). Gland, Switzerland: IUCN. $\mathrm{Xiv}+262 \mathrm{p} . \mathrm{pp} 3-9$.

[13] Bees for Development, 2008. Best hive type for Africa. Bees for Development Journal, Web site: http://www.beesfordevelopment.org/portal/article.php?id=121 4.

[14] Pye-Smith C., 2010. The Fruits of Success: A programme to domesticate West and Central Africa's wild fruit trees is raising incomes, improving health and stimulating the rural economy. Edited by ICRAF, Trees for Change No. 4. Nairobi: World Agroforestry Centre.

[15] RAPAC, 2009. Sub-regional workshop-workshop on the development of tools and management methods for protected areas in Central Africa. General Report. Brazzaville, 10-13 February 2009, Republic of Congo. p 60.

[16] FAO, JRC, SDSU and UCL, 2009. The Global Forest Resources Assessment Remote Sensing Survey: an outline of the objectives, data, methods and approach. Forest Resources Assessment Working Paper 155. Published by FAO with FRA RSS partners, Italy. 